\title{
NATURAL CONVECTION HEAT TRANSFER INSIDE VERTICAL AND INCLINED OPEN ENDED EQUILATERAL TRIANGULAR CHANNELS
}

\author{
Mahmoud S. Ahmed ${ }^{1}$, Hany A. Mohamed ${ }^{2}$, \\ Mohamed A. Omara ${ }^{3}$, and Mohamed F. Abdeen ${ }^{4, *}$ \\ ${ }^{1}$ Mechanical Eng. Department, Faculty of Industrial Education, Sohag University, Sohag, Egypt \\ ${ }^{2}$ Mechanical Engineering Department, Faculty of Engineering, Assiut University, Assiut, Egypt \\ ${ }^{3}$ Mechanical Eng. Department, Faculty of Industrial Education, Suez University, Suez, Egypt \\ ${ }^{4}$ Instructors, Industrial Technical Institute of Sohag, Sohag, Egypt
}

Received 1 January 2013; accepted 4 May 2013

\begin{abstract}
Experimental study of natural convection heat transfer inside smooth and rough surfaces of vertical and inclined equilateral triangular channels of different inclination angles with a uniformly heated surface are performed. The inclination angle is changed from $15^{\circ}$ to $90^{\circ}$. Smooth and rough surface of average roughness $(0.02 \mathrm{~mm})$ are used and their effect on the heat transfer characteristics are studied. The local and average heat transfer coefficients and Nusselt number are obtained for smooth and rough channels at different heat flux values, different inclination angles and different Rayleigh numbers (Ra) $6.48 \times 10^{5} \leq \mathrm{Ra} \leq 4.78 \times 10^{6}$. The results show that the local Nusselt number decreases with increase of axial distance from the lower end of the triangular channel to a point near the upper end of channel, and then, it slightly increases. Higher values of local Nusselt number for rough channel along the axial distance compared with the smooth channel. The average Nusselt number of rough channel is higher than that of smooth channel by about $8.1 \%$ for inclined case at $\theta$ $=45^{\circ}$ and $10 \%$ for vertical case. The results obtained are correlated using dimensionless groups for both rough and smooth surfaces of the inclined and vertical triangular channels.
\end{abstract}

Key words: Natural Convection, Constant heat flux, Triangular Channels, Rough surface, Smooth Surface

\section{Introduction}

Natural convection heat transfer has gained considerable attention because of its applications in many practical fields in the area of energy conservation, design of solar collectors, heat exchangers, nuclear engineering, cooling of electrical and electronic equipment and many others. The increasing interest in developing compact and highly efficient heat exchangers motivated researchers to study heat transfer from tubes of noncircular cross section,(elliptic, rectangular, square, ... etc). Abdel-Aziz [1] studied the heat transfer by natural convection from the inside surface of a uniformly heated tube at different angles of inclination. The experiments were carried out in the range of $R a$ from $1.44 \times 10^{7}$ to $8.85 \times 10^{8}$, L/D from 10 to 31.4 and angle of inclination from $0^{\circ}$ to $75^{\circ}$ degree. The results showed that the average $\mathrm{Nu}_{\mathrm{m}}$ had a maximum value when the tube was vertical.

Hussein and Yasin [2] experimentally investigated Heat transfer by natural convection from a uniformly heated vertical circular pipe with different entry restriction configurations by using the boundary condition of constant wall heat flux in the ranges of $R a$ from $1.1 \times 10^{9}$ to $4.7 \times 10^{9}$. The apparatus was made from heated cylinder of a length

Corresponding author.

Email address: mohamedfa2020@yahoo.com 
Mohamed F. Abdeen et al., Natural convection heat transfer inside vertical and inclined open ended equilateral triangular channels, pp. 2160 - 2174

$900 \mathrm{~mm}$ and inside diameter $30 \mathrm{~mm}$. The results show that the Nusselt number values increase as the heat flux increases. Empirical correlations were proposed in the form of $\operatorname{LogNu} u_{m}$ versus $\operatorname{LogRa} a_{m}$ for each case investigated and a general correlation was obtained for all cases.

Sarhan et al. [3] studied the problem of natural convection to the air from the inside surface of the outer tube of the horizontal and vertical annuli with a uniformly heated outer tube and an adiabatic inner tube. The experiments covered a range of radius ratio from 0.26 to 0.71 and a range of $R a(D / L)$ from $1.05 \times 10^{2}$ to $1.2 \times 10^{4}$. The results obtained were correlated by dimensionless groups with the available data of vertical annuli. The results showed that the cooling by natural convection inside the annuli decreased with the increase of radius ratio.

Hosseini et al. [4] free convection in an open-ended vertical eccentric annulus with different eccentric ratios has been experimentally studied with several heat fluxes. The outer pipe was heated electrically and insulated carefully from the environment, and the inner pipe was completely filled with the ceramic wool to maintain the inner boundary insulated. The length and the radius ratio of the pipes used were $1660 \mathrm{~mm}$ and 0.24 , respectively. The analysis of experimental results indicates that the heat transfer coefficient increases as the eccentric ratio increases up to 0.5 . For ratios $0.5-0.7$ the heat transfer coefficient remains approximately constant, and beyond that it starts to decrease and reaches a minimum at an eccentric ratio of 1 .

Free convection heat transfer from the inside surface of the inclined and vertical elliptic tube of axis ratio 2:1 with a uniformly heated outer surface was experimentally studied by Omara et al. [5] and Moawed and Ibrahim [6] The orientation angle $(\alpha)$ was changed from $0^{\circ}$ to $90^{\circ}$ with a step of $15^{\circ}$ and the inclination angle $(\theta)$ was changed from $15^{\circ}$ to $90^{\circ}$ with steps of $15^{\circ}$. The experiments covered a range of Rayleigh number, $(\mathrm{Ra})$ from $2.6 \times$ $10^{6}$ to $3.6 \times 10^{7}$ for Omara et al. [5] and $6.85 \times 10^{5}$ to $1.3 \times 10^{8}$ for Moawed and Ibrahim [6]. The local and average Nusselt numbers were estimated for different orientation angles $(\alpha)$ and inclination angles $(\theta)$ at different Rayleigh numbers. It was found that the temperature increases with the increase of axial distance from lower end of the elliptic tube to the maximum value near the upper end. Then, the temperature gradually decreased. Also, local $\mathrm{Nu}_{\mathrm{x}}$ was increased with the increase of $\alpha$ at the same axial distance. The mean Nusslet was increased with the increase of both $\alpha$ and $\theta$.

Amr et al. [7] conducted an experimental investigation of free convection from the outer surface of an elliptic tube to air for case of constant heat flux. The local and average Nusselt number are obtained for elliptic tube at different inclination angles and different values of Rayleigh number $1.1 \times 10^{7} \leq \mathrm{Ra} \geq 8 \times 10^{7}$. The comparison between free convection around isothermal and constant heat flux elliptic tubes, it was made and it was found that at steady state, the heat flux tube correlates well with Rayleigh number similar to the isothermal tube. The maximum average Nusselt number is achieved by the elliptic tube with vertical major axis.

Nada [8] studied natural convection heat transfer in horizontal and vertical closed narrow enclosures with heated rectangular finned base plate. The study was experimentally investigated at a wide range of Rayleigh number ( $\mathrm{Ra}$ ) for different fin spacing and fin length values. The results show that increasing fin length increases Nusselt number $\left(\mathrm{Nu}_{\mathrm{m}}\right)$

Journal of Engineering Sciences, Assiut University, Faculty of Engineering, Vol. 41, No. 6, November, 2013, E-mail address: jes@aun.edu.eg 
Mohamed F. Abdeen et al., Natural convection heat transfer inside vertical and inclined open ended equilateral triangular channels, pp. 2160 - 2174

and finned surface effectiveness $(\varepsilon)$; also increasing $\mathrm{Ra}$ increases $\mathrm{Nu}_{\mathrm{m}}$ for any fin-array geometry.

Varol et al. [9] studied natural convection in a triangular enclosure with flush mounted heater on the wall. The study of natural convection heat transfer in triangular enclosure was analyzed numerically for different parameters, including the aspect ratio of triangle $(\mathrm{AR}=1$ and 0.6), Rayleigh number and both length and position of heater. The results showed that the flow and temperature fields are affected by the shape of enclosure and Rayleigh numbers play an important role on them. Both position and location of heater affect the flow circulation and heat transfer.

Experimental study of inclination angle and surface area effects for longitudinally finned cylinder on free convection heat transfer in an open enclosure was studied by Seleem and Kamel [10]. This study deals with heat transfer by free convection from the outer surface of two cylinders (Triangular \& Rectangular shape fined cylinder 12-fins). The experimental work was conducted with air as a heat transport medium. The cylinders were fixed at different slope angles $\left(0^{\circ}, 30^{\circ}, 60^{\circ}, 90^{\circ}\right)$. The results show that heat transfer from the triangular finned cylinder is a maximum at a slope angle $\left(90^{\circ}\right)$ and minimum at the slope angle $\left(0^{\circ}\right)$ with the range of, Ra, from $1.54 \times 10^{7}$ to $1.57 \times 10^{8}$.

Abdlmonem and Michel [11] studied the effect of surface roughness on the average heat transfer from a uniformly heated flat plate of an impinging air jet. The roughness took the shape of a circular array of protrusions of $0.5 \mathrm{~mm}$ base and $0.5 \mathrm{~mm}$ height. The results indicated an increase up to $6.0 \%$ of the average Nusselt number due to surface roughness. Heat transfer in rough circular cylinder microfins was studied and a new analytical model was also developed by Majid et al. [12]. The results showed that both cross-sectional and surface areas of microfins increase by increasing roughness. Consequently, an enhancement is observed in the heat transfer rate and thermal performance of microfins. The effect of roughness is more profound in lower convective heat transfer coefficient. The rate of increase in microfin base heat flux due to roughness is higher at lower Nusselt numbers; thus, better improvement in thermal efficiency of a microfin (due to roughness) can be achieved with a natural convection regime.

Hany et al. [13] natural convection heat transfer through horizontal open ended equilateral triangular channels (smooth and rough channels) with a uniformly heated surface is experimentally study. The effect of smooth and rough surface of average roughness $\left(\mathrm{r}_{\mathrm{a}}=\right.$ $0.02 \mathrm{~mm}$ ) on the heat transfer characteristics are studied. The local and average heat transfer coefficients and Nusselt number were obtained for smooth and rough channels at different Rayleigh numbers from $6.45 \times 10^{5}$ to $4.45 \times 10^{6}$. The findings show that the values of temperature difference between the inside surface and ambient air increases with increase of axial distance from both ends of the channel until a maximum value at the middle of the channel. The results show higher values of local $\left(\mathrm{Nu}_{\mathrm{x}}\right)$ for rough channel along the axial distance compared with the smooth channel. The average $\mathrm{Nu}_{\mathrm{m}}$ of rough channel is higher than $\mathrm{Nu}_{\mathrm{m}}$ of smooth channel by about $7 \%$. The results obtained were correlated using dimensionless groups for both rough and smooth surfaces of the equilateral horizontal triangular channels.

Journal of Engineering Sciences, Assiut University, Faculty of Engineering, Vol. 41, No. 6, November, 2013, E-mail address: jes@aun.edu.eg 
Mohamed F. Abdeen et al., Natural convection heat transfer inside vertical and inclined open ended equilateral triangular channels, pp. 2160 - 2174

In the present work natural convection heat transfer from vertical and inclined open ended equilateral triangular channel to inside air is experimentally studied. The effect of the inner surfaces roughness is taken into considerations.

\section{Experimental Set Up and Test Procedures}

The experimental test rig is shown diagrammatically in Fig. 1. It consists of an equilateral triangular channel (test section) mounted on a frame.

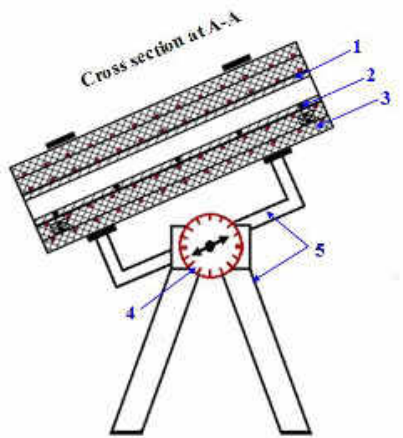

Fig. 1. Experimental setup

4-Protractor.

5- Frame.

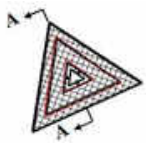

1- Triangular channel.

2-Thermocouples.

3-Asbestos layers.

The equilateral triangular channel of length $500 \mathrm{~mm}$ is made from copper of $1.5 \mathrm{~mm}$ thickness. Side length of triangle for equilateral triangular channel is $65 \mathrm{~mm}$. The outer surface of the triangular channel is completely covered with an electricity insulating tape as shown in Fig. 2. A nickel-chrome wire of $0.4 \mathrm{~mm}$ diameter is uniformly wound to form the main heater. The main heater is covered with an asbestos layer of $45 \mathrm{~mm}$ thickness surrounded by another nickel-chrome wire of $0.4 \mathrm{~mm}$ diameter was wound uniformly to form a guard heater. The guard heater is covered with a $30 \mathrm{~mm}$ thick asbestos layer. Two pairs of thermocouples are installed in the asbestos layer between the main heater and the guard heater. The thermocouples of each pair were fixed on the same radial line. The guard heater is adjusted so that, at steady state, the readings of the thermocouples of each pair became practically the same. Thus, all the energy generated by the main heater should be flown inward to the triangular channel.

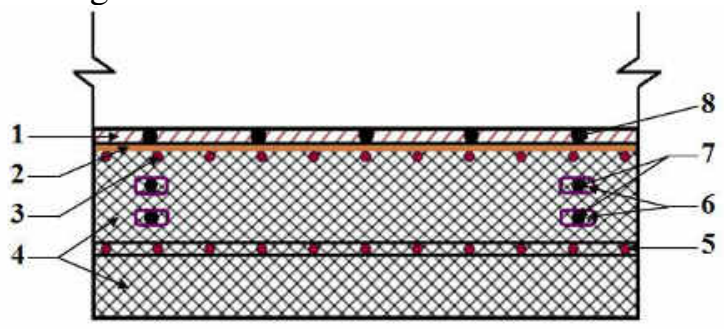
1. Triangular channel.
2. Electricity insulation.
3. Main heater.
4. Asbestos layers.
5. Guard heater.
6. Aluminium strips.
7. Pair of Thermocouples. 8.Thermocouples.

Fig. 2. Heaters arrangement

Journal of Engineering Sciences, Assiut University, Faculty of Engineering, Vol. 41, No. 6, November, 2013, E-mail address: jes@aun.edu.eg 
Mohamed F. Abdeen et al., Natural convection heat transfer inside vertical and inclined open ended equilateral triangular channels, pp. 2160 - 2174

The inner surface temperature of the triangular channel is measured by 15 chromel-alumel thermocouples of $0.4 \mathrm{~mm}$ diameter soldered in slots milled along the axial and circumferential directions. The distribution of thermocouples is located for five measuring axial locations for each side surface of the triangular channel at axial distances of 50, 150, 250, 350 and $450 \mathrm{~mm}$ from one end of the triangular channel as shown in Fig. 3.

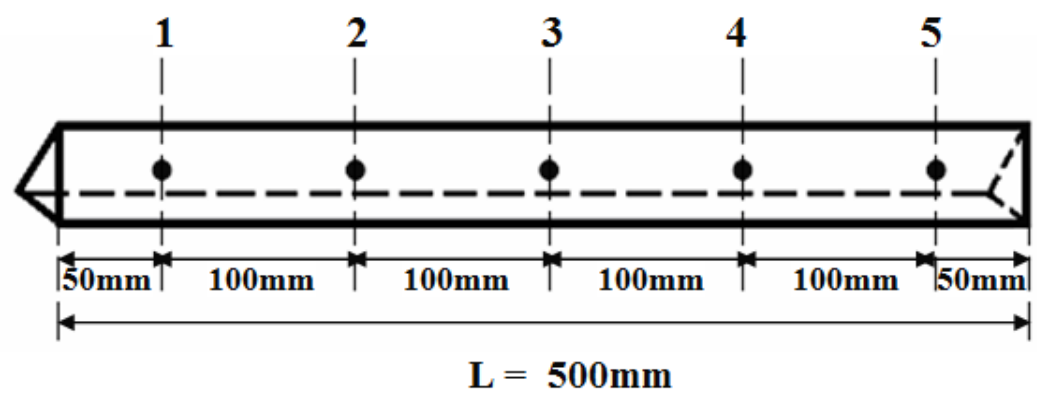

Fig. 3. Distribution of the thermocouples on the triangular channel.

The calculation of heat transfer coefficient is depending on the temperature difference $\left(\Delta \mathrm{T}_{\mathrm{s}}\right)$ between the inside surface temperature and the bulk temperature of the air flowing inside the triangular channel. The bulk temperature is, however, unknown. Consequently the heat transfer coefficient is calculated employing a temperature difference equal to the difference between the surface temperature $T_{\mathrm{s}}$ and the temperature at the entrance to the triangular channel. All temperatures are measured by digital thermometer capable of reading $\pm 0.1 \mathrm{C}$. The input electric power was regulated by $\mathrm{AC}$ power voltage transformer (variac) and is measured by a digital wattmeter with a resolution of $\pm 0.01 \mathrm{~W}$. The whole experimental set up was installed in laboratory room (closed room) with a controlled temperature environment. The input electric power to the main heater is controlled and changed by the AC variac for each experiment. The steady state condition for each run was achieved after $3-4 \mathrm{~h}$ approximately. The steady state condition is considered to be achieved when the temperature reading of each thermocouple was not changed by more than $\pm 0.5 \mathrm{C}$ within 20 minutes. When the steady state condition was established, the readings of all thermocouples and the input power were recorded. Two equilateral triangular channels, one has smooth surfaces and the second has rough surface of $0.02 \mathrm{~mm}$ roughness were used for the present study.

\section{Analysis of Experimental Measurements}

In the present work, the local heat transfer coefficient, $h_{\mathrm{x}}$, between the inside surface of the triangular channel and the air inside the triangular channel is calculated by:

$$
h_{x}=q / \Delta T_{s}
$$

The temperature difference between the inside surface of the triangular channel and the

bulk air is given by:

$$
\Delta T_{s}=\left(T_{s}-T_{\infty}\right)
$$

The corresponding local Nusselt number, $\mathrm{Nu}$ is calculated from by:

$$
N u_{x}=h_{x} D / k
$$

Journal of Engineering Sciences, Assiut University, Faculty of Engineering, Vol. 41, No. 6, November, 2013, E-mail address: jes@aun.edu.eg 
Mohamed F. Abdeen et al., Natural convection heat transfer inside vertical and inclined open ended equilateral triangular channels, pp. 2160 - 2174

The average heat transfer coefficient between the inside surface of the triangular channel and the air inside the triangular channel is calculated from the following equation:

$$
h_{m}=q / \Delta T_{m s}
$$

Where: $\Delta T_{m s}=T_{m s}-T_{\infty}$

The average inner surface temperature can be estimated by:

$$
T_{m s}=\frac{1}{L} \int_{x=0}^{x=L} T_{s x} d x
$$

The corresponding average Nusselt number $\mathrm{Nu}_{\mathrm{m}}$ is calculated by:

$$
N u_{m}=h_{m} D / k
$$

The Rayleigh number $\mathrm{Ra}$ is calculated by:

$$
R a=G r P r
$$

The Grashof number, Gr can be calculated by:

$$
G r=g \beta D^{4} q / k v^{2}
$$

The physical properties are evaluated at the mean film temperature, as in [16] as:

$$
T_{m f}=\left(T_{m s}+T_{\infty}\right) / 2
$$

\section{Uncertainty Analysis}

Generally, the accuracy of the experimental results depends upon the accuracy of the individual measuring instrument and the manufactured accuracy of the triangular channel. Also, the accuracy of an instrument is limited by its minimum division (its sensitivity). In the present work, the uncertainties in both the heat transfer coefficient (Nusselt number) and Rayleigh number are estimated by using the differential approximation method. For a typical experiment, the total uncertainty in measuring the main heater input power, temperature difference $\left(\Delta \mathrm{T}_{\mathrm{s}}\right)$, heat transfer rate and the triangular channel surface area were $\pm 0.23 \%, \pm 0.6 \%, \pm 3.1 \%$ and $\pm 0.23 \%$, respectively. These are combined to give a maximum error of $\pm 3.7 \%$ in heat transfer coefficient (Nusselt number) and a maximum error of $\pm 5.2 \%$ in Rayleigh number.

\section{Results and Discussion}

The present experimental results for smooth and rough surfaces of vertical and inclined triangular channels with different heat flux values $(q)$, different inclination angles $(\theta)$ and different Rayleigh numbers ( $\mathrm{Ra}$ ) are discussed in this section. The results obtained in this work include the temperature distributions of channel surface temperature and local $\mathrm{Nu}_{\mathrm{x}}$ as well as $\mathrm{Nu}_{\mathrm{m}}$ vs $\mathrm{Ra}$. The results covered ranges of Ra from $6.48 \times 10^{5}$ to $4.78 \times 10^{6}$, for both smooth and rough surfaces (average roughness $\left.r_{a}=0.02 \mathrm{~mm}\right)$ of the inclined $\left(15^{\circ} \leq \theta \leq 75^{\circ}\right)$ and vertical $\left(\theta=90^{\circ}\right)$ triangular channels.

\subsection{Temperature difference distribution}

The results for the inside surface temperature difference $\left(\Delta \mathrm{T}_{\mathrm{s}}\right)$ of the smooth triangular channel are shown in Fig. 4 for the inclined case at $\theta=15^{\circ}$. This figure shows a parabolic variation of the temperature difference $\left(\Delta \mathrm{T}_{\mathrm{s}}\right)$ with axial distance $(\mathrm{x})$ for inner smooth surface. The surface temperature difference $\left(\Delta \mathrm{T}_{\mathrm{s}}\right)$ gradually increase with the increase of

Journal of Engineering Sciences, Assiut University, Faculty of Engineering, Vol. 41, No. 6, November, 2013, E-mail address: jes@aun.edu.eg 
Mohamed F. Abdeen et al., Natural convection heat transfer inside vertical and inclined open ended equilateral triangular channels, pp. 2160 - 2174

axial distance $(\mathrm{x})$ from the lower end of the inclined triangular channel until a maximum value near the upper end of triangular channel, then, it slightly decreases. This can be attributed to the flow of cold air entering from the lower end flowing up to the upper end due to buoyancy effect. This flow causes grow of boundary layer from the lower end until the boundary layer fills the whole triangular channel. This would, however, cause the surface temperature difference to increase.

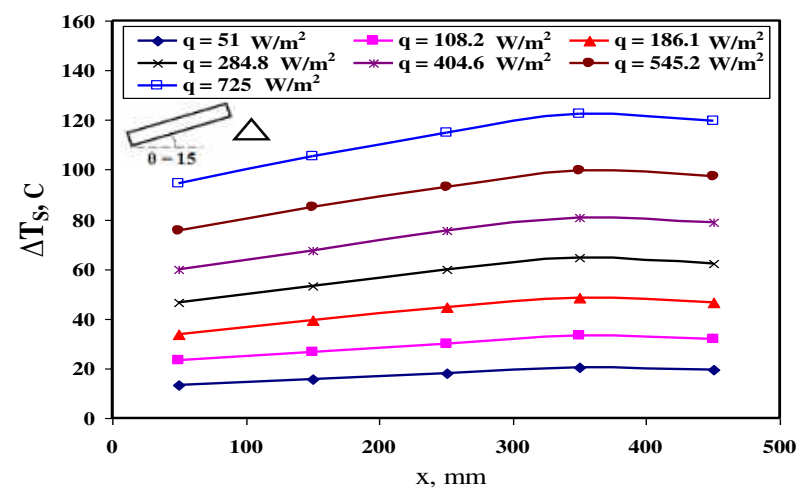

Fig. 4. Variation of surface temperature difference $\left(\Delta T_{s}\right)$ with axial distance $(x)$ for smooth triangular channel at different values of heat flux and $\theta=15^{\circ}$.

Figure 5 shows a behavior of $\Delta \mathrm{Ts}-\mathrm{x}$ for vertical triangular channel similar to that of inclined triangular channel with $\theta=15^{\circ}$ but different in $\Delta$ Ts values. Also, behaviors of stream lines of air flow inside the vertical triangular channel are different from that of the inclined triangular channels. All the air flowing inside the channel enters from the lower end and all of it exits from the upper end.

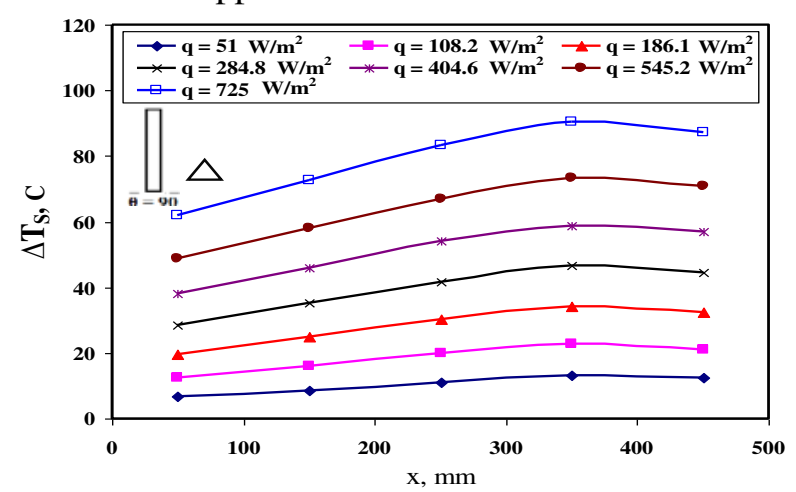

Fig. 5. Variation of surface temperature difference $\left(\Delta T_{s}\right)$ with axial distance $(x)$ for smooth triangular channel at different values of heat flux and $\theta=90^{\circ}$.

Figure 6 shows the effect of inclination angle $\theta$ on $\Delta T_{\mathrm{s}}$ at one value of heat flux (404.6 $\mathrm{W} / \mathrm{m}^{2}$ ) for triangular channel. It can be seen from this figure that the temperature difference $\Delta \mathrm{T}_{\mathrm{s}}$ decreases with increase of inclination angle, $(\theta)$ at the same axial distance, (x) and the same heat flux, (q). This can be attributed to the increase of air flow and its temperature with increase of channel inclination. Thus, causes a high rate of convective

Journal of Engineering Sciences, Assiut University, Faculty of Engineering, Vol. 41, No. 6, November, 2013, E-mail address: jes@aun.edu.eg 
Mohamed F. Abdeen et al., Natural convection heat transfer inside vertical and inclined open ended equilateral triangular channels, pp. 2160 - 2174

heat transfer between the inner surface of the triangular channel and the air inside the triangular channel and causes reduction in $\Delta \mathrm{T}_{\mathrm{s}}$.

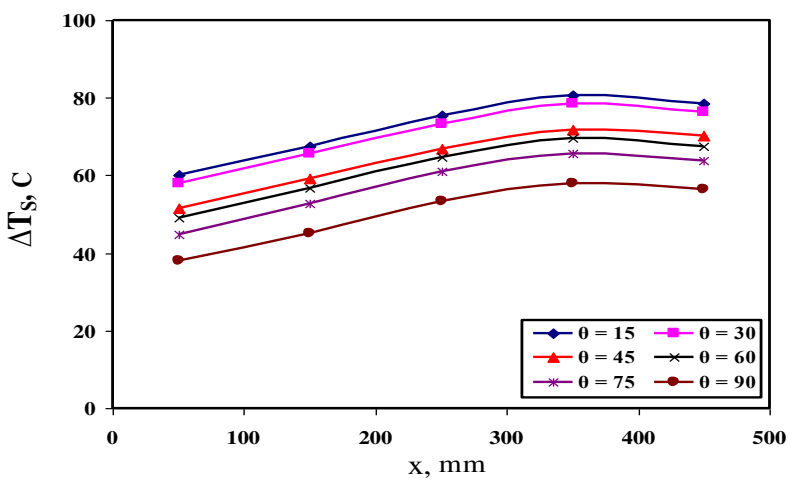

Fig. 6. Effect of the inclination angle $(\theta)$ on surface temperature difference $\left(\Delta T_{s}\right)$ of smooth triangular channel at $\mathrm{q}=404.6 \mathrm{~W} / \mathrm{m}^{2}$.

\subsection{Local nusselt number, $N u_{x}$}

Figure 7 illustrates the variation of local Nusselt number $\left(\mathrm{Nu}_{\mathrm{x}}\right)$ along the axial distance of the inclined triangular channel at $\theta=15^{\circ}$ and different heat fluxes. As shown from this figure the $\mathrm{Nu}_{\mathrm{x}}$ decreases with the increase of dimensionless axial distance $(\mathrm{x} / \mathrm{L})$ from the lower end of the inclined triangular channel until a minimum value near the upper end of channel, then, it slightly increases until the upper end of triangular channel. The boundary layer grows up causing a decrease in convective heat transfer coefficient.

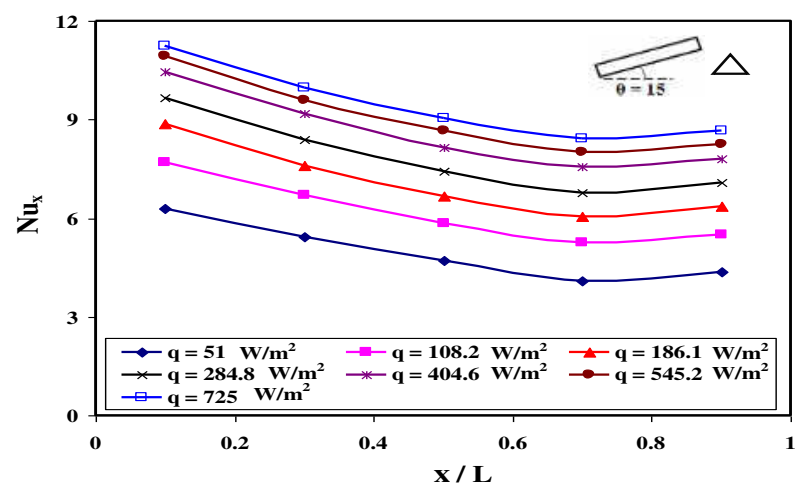

Fig. 7. Variation of the local Nusselt number $\left(\mathrm{Nu}_{\mathrm{x}}\right)$ with axial distance $(\mathrm{x} / \mathrm{L})$ for smooth triangular channel at $\theta=15^{\circ}$.

Journal of Engineering Sciences, Assiut University, Faculty of Engineering, Vol. 41, No. 6, November, 2013, E-mail address: jes@aun.edu.eg 
Mohamed F. Abdeen et al., Natural convection heat transfer inside vertical and inclined open ended equilateral triangular channels, pp. $2160-2174$

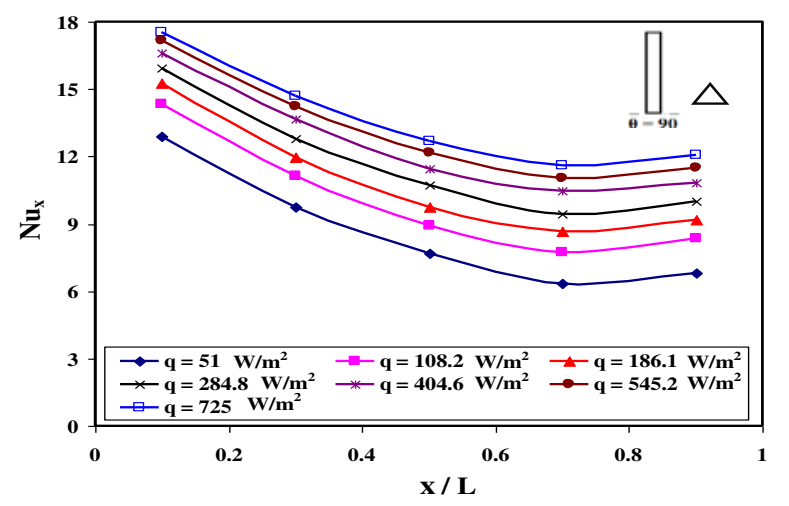

Fig. 8. Variation of the local Nusselt number $\left(\mathrm{Nu}_{\mathrm{x}}\right)$ with axial distance $(\mathrm{x} / \mathrm{L})$ for smooth triangular channel at $\theta=90^{\circ}$.

The effect of inclination angle $\theta$ on local Nusselt number $\mathrm{Nu}_{\mathrm{x}}$ of triangular channel is shown in Fig. 9. This figure shows that $\mathrm{Nu}_{\mathrm{x}}$ increases with increase of $\theta$ under the same other conditions. This can be attributed to the increase of air drawn from the lower end due to buoyancy force. Thus, causes increase convective heat transfer rate with the increase of $\theta$.

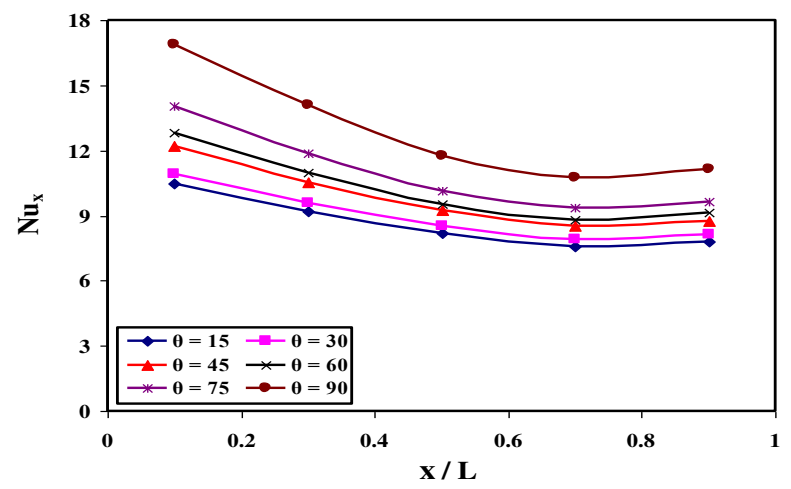

Fig. 9. Effect of the inclination angle $(\theta)$ on local Nusselt number $\left(\mathrm{Nu}_{\mathrm{x}}\right)$ of smooth triangular channel at $\mathrm{q}=404.6 \mathrm{~W} / \mathrm{m}^{2}$.

\subsection{Mean nusselt number, $N u_{m}$}

Figure 10 shows the effect of inclination angle $(\theta)$ on the average $\mathrm{Nu}_{\mathrm{m}}$ at different heat fluxes for the smooth triangular channel. This figure shows that, the average $\mathrm{Nu}_{\mathrm{m}}$ increases with the increase of $(\theta)$ at the same heat flux. The increasing of $\mathrm{Nu}_{\mathrm{m}}$ with increase of $(\theta)$ can be attributed to the increase of air flow due buoyancy force through the lower end of the triangular channel. 
Mohamed F. Abdeen et al., Natural convection heat transfer inside vertical and inclined open ended equilateral triangular channels, pp. 2160 - 2174

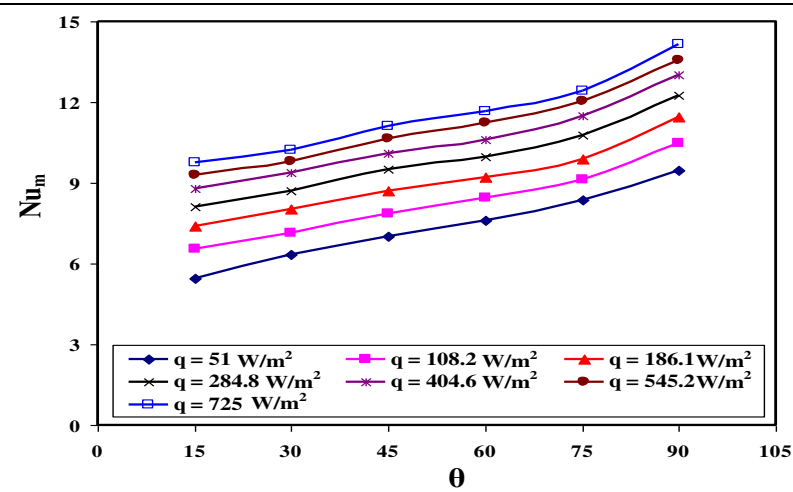

Fig. 10. Effect of The inclination angle $(\theta)$ on the $\left(\mathrm{Nu}_{\mathrm{m}}\right)$ at different heat fluxes for smooth triangular channel.

The variation of the average Nusselt number, $\mathrm{Nu}_{\mathrm{m}}$, with $\mathrm{Ra}$ at different inclination angle $(\theta)$ is shown in Fig. 11 for smooth triangular channel. As shown $\mathrm{Nu}_{\mathrm{m}}$ increases with the increase of $\theta$ and Ra.

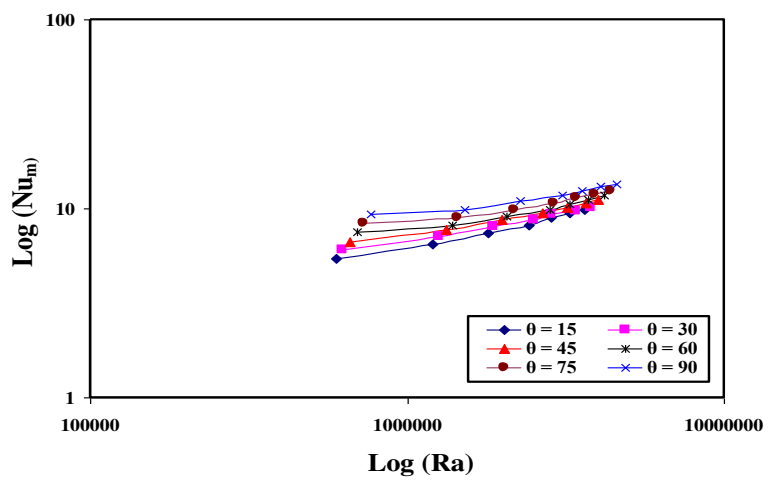

Fig. 11. Variation of mean Nusselt number $\left(\mathrm{Nu}_{\mathrm{m}}\right)$ with Rayliegh number at different inclination angels.

The variation of the average Nusselt number, $\mathrm{Nu}_{\mathrm{m}}$, with $\mathrm{Ra}$ for smooth and rough channels at different inclination angles $\left(15^{\circ}, 45^{\circ}\right.$ and $\left.90^{\circ}\right)$ is shown in Fig. 12. This figure shows that the value of $\mathrm{Nu}_{\mathrm{m}}$ increases with the increase of $\mathrm{Ra}$ for smooth and rough inside surfaces. Comparing $\mathrm{Nu}_{\mathrm{m}}$ versus $\mathrm{Ra}$ for smooth and rough inside surfaces shows that $\mathrm{Nu}_{\mathrm{m}}$ values for rough surface are higher than $\mathrm{Nu}_{\mathrm{m}}$ values for smooth surface at all cases.

Journal of Engineering Sciences, Assiut University, Faculty of Engineering, Vol. 41, No. 6, November, 2013, E-mail address: jes@aun.edu.eg 
Mohamed F. Abdeen et al., Natural convection heat transfer inside vertical and inclined open ended equilateral triangular channels, pp. 2160 - 2174

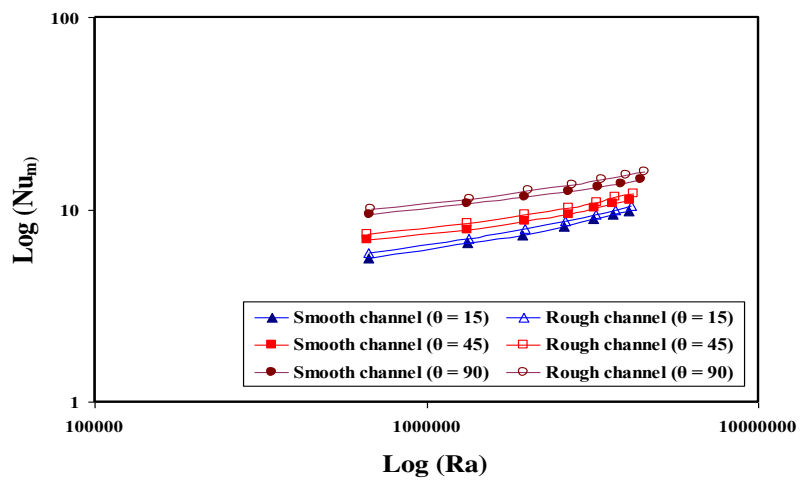

Fig. 12. Comparison between smooth and rough triangular channels on the average Nusselt number $\left(\mathrm{Nu}_{\mathrm{m}}\right)$ for different values of $\mathrm{Ra}$, at different inclination angles.

\subsection{Correlation of the results}

The experimental results were fitted using power regression. Evaluations of the empirical correlations for both smooth and rough surface channels are as follows:

\section{Smooth and rough triangular channels at $\left(15^{\circ} \leq \theta \leq 90^{\circ}\right)$ :}

For smooth channel

$\mathrm{Nu}_{\mathrm{m}}=0.11 \mathrm{Ra}^{0.304}(\sin \theta)^{0.013}, \quad 6.48 \times 10^{5} \leq \mathrm{Ra} \leq 4.69 \times 10^{6}$

For rough channel $\left(r_{a}=0.02 \mathrm{~mm}\right)$
$\mathrm{Nu}_{\mathrm{m}}=0.12 \mathrm{Ra}^{0.304}(\sin \theta)^{0.013}$,
$6.49 \times 10^{5} \leq \mathrm{Ra} \leq 4.78 \times 10^{6}$

Equations (10) and (11) represent the correlation for natural convection inside smooth and rough equilateral triangular channels respectively at $6.48 \times 10^{5} \leq \mathrm{Ra} \leq 4.78 \times 10^{6}$ and $15^{\circ} \leq$ $\theta \leq 90^{\circ}$. The calculated data from Equations (10) and (11) of the average Nusselt number $\left(N u_{m C a l}\right)$ are plotted against experimental data of the average Nusselt number $\left(N u_{m E x p}\right)$ in Fig. 13 (a) \& (b). As noted from figure, the maximum deviation between the experimental data and the correlated equations are $\pm 9.7 \%$ for smooth channel and $\pm 10.5 \%$ for rough channel.

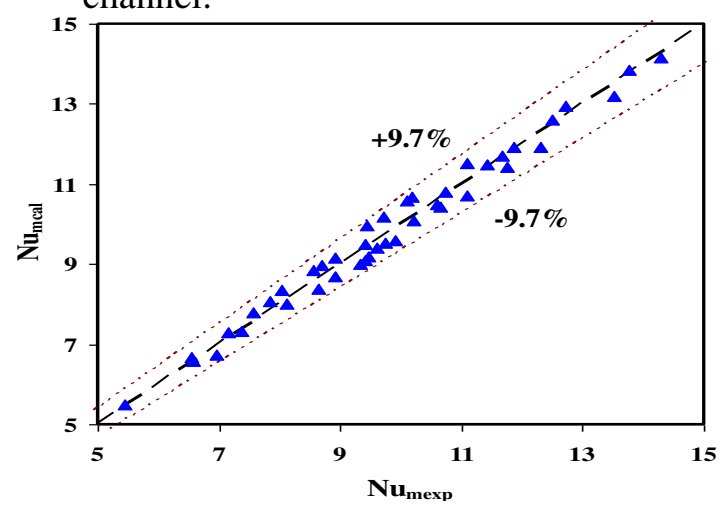

(a) Smooth channel

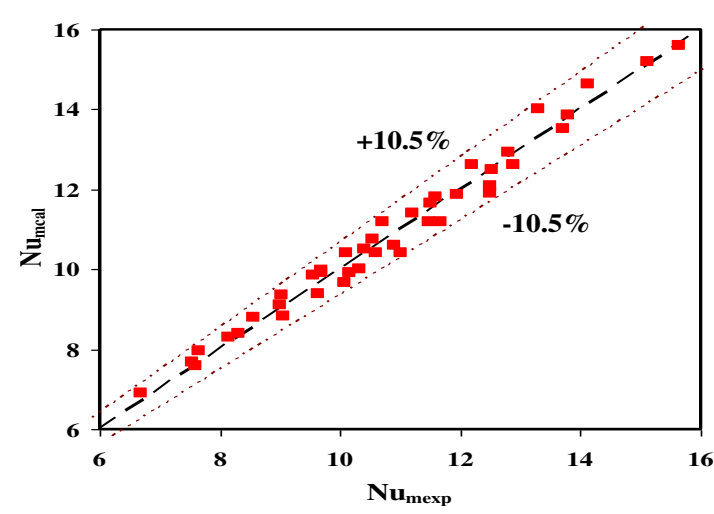

(b) Rough channel

Fig. 13. Average $N u_{\text {mcal }}$ versus Average $N u_{\text {mexp }}$ for smooth and rough triangular channels at $\left(15^{\circ} \leq \theta \leq 90^{\circ}\right)$

Journal of Engineering Sciences, Assiut University, Faculty of Engineering, Vol. 41, No. 6, November, 2013, E-mail address: jes@aun.edu.eg 
Mohamed F. Abdeen et al., Natural convection heat transfer inside vertical and inclined open ended equilateral triangular channels, pp. 2160 - 2174

\subsection{Comparison with the previous work}

\subsubsection{Inclined channels}

The available information about free convection from inclined elliptic tube of Moawed and Ibrahim [6] is used for comparison. The present experimental data of inclined triangular channels (smooth and rough channels) at $\theta=45^{\circ}$, it's compared with the inclined elliptic tube at $\theta=45^{\circ}$ of Moawed and Ibrahim [6] is shown in Fig. 14. This figure shows that the present results of free convection heat transfer inside inclined triangular channels are less than Moawed and Ibrahim [6] for free convection heat transfer inside inclined elliptic channel. Also, there is enhancement of free convection heat transfer in using triangular rough channel at different inclination angles instead of triangular smooth channel at the same working conditions.

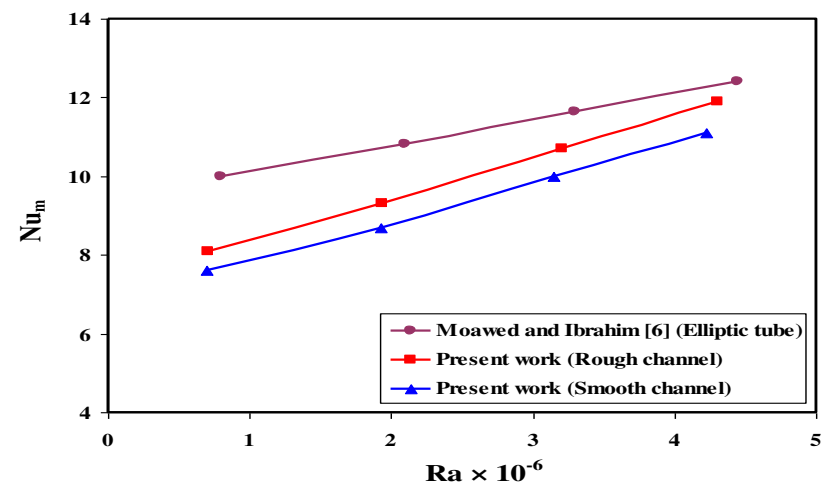

Fig. 14. Comparison of the present work versus Moawed and Ibrahim [6].

\subsubsection{Vertical channels}

A comparison between the present work results with Omara et al. [5] is shown in Fig. 15. This figure shows that the present results of free convection heat transfer inside vertical triangular channels are less than Omara et al. [5] for free convection heat transfer inside vertical elliptic channel. Also, there is enhancement of free convection heat transfer in using triangular rough channel instead of triangular smooth channel at the same working conditions.

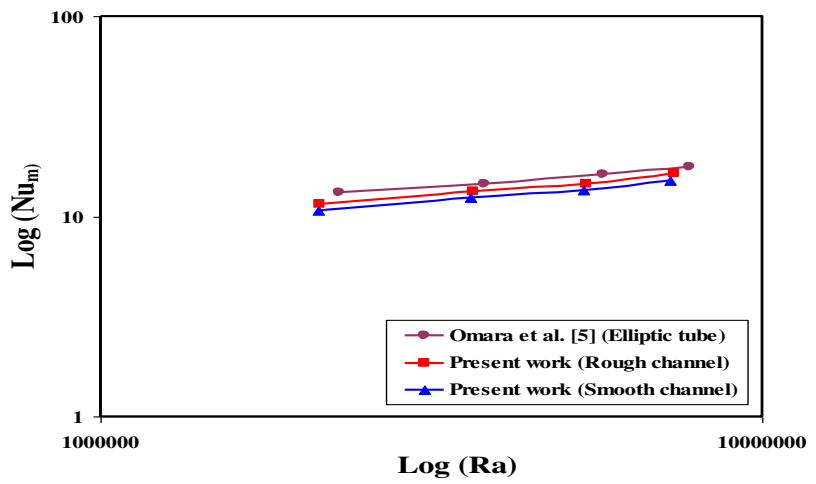

Fig. 15. Comparison of the present work versus Omara et al. [5].

Journal of Engineering Sciences, Assiut University, Faculty of Engineering, Vol. 41, No. 6, November, 2013, E-mail address: jes@aun.edu.eg 
Mohamed F. Abdeen et al., Natural convection heat transfer inside vertical and inclined open ended equilateral triangular channels, pp. 2160 - 2174

\section{Conclusions}

Natural convection heat transfer from the inside surface of vertical and inclined equilateral triangular channels to air with a uniformly heated surface is investigated experimentally. The average roughness of rough channel was $\left(r_{a}=0.02 \mathrm{~mm}\right)$. The experiments covered a range of Rayleigh number, Ra from $6.48 \times 10^{5}$ to $4.78 \times 10^{6}$. The local and average Nusselt number values are estimated for smooth and rough channels at different values of Rayleigh numbers. The following main points can be drawn from this study:

- The value of the local $\mathrm{Nu}_{\mathrm{x}}$ in rough channel is higher than $\mathrm{Nu}_{\mathrm{x}}$ in smooth channel.

- The local Nusselt number $\left(\mathrm{Nu}_{\mathrm{x}}\right)$ decreases with increase of axial distance from the lower end of the triangular channel to a point near the upper end of channel, and then, it gradually increases.

- The average $\mathrm{Nu}_{\mathrm{m}}$ increases with increasing $\mathrm{Ra}$.

- There is an enhancement of heat transfer coefficient with rough surface and increase of inclination angle $(\theta)$ at the same heat flux $(q)$,the average heat transfer coefficient $\left(\mathrm{h}_{\mathrm{m}}\right)$ of rough channel is higher than that of smooth channel by about $8.1 \%$ in inclined case at $\theta=45^{\circ}$ and $10 \%$ in vertical case.

- Correlations of Nusselt number for natural convection inside open ended inclined and vertical equilateral triangular channels (smooth and rough channels) are obtained.

\section{Nomenclature}

$A_{c} \quad$ Cross-sectional area, $\mathrm{m}^{2}$

$A_{s} \quad$ Surface area, $\mathrm{m}^{2}$

$C$ Constant

$c_{p} \quad$ Specific heat of air at constant pressure, $\mathrm{J} / \mathrm{kg} \mathrm{K}$

$D$ Hydraulic diameter of triangular channel, $4 \mathrm{~A}_{\mathrm{c}} /$ per, $\mathrm{m}$

$g \quad$ Gravity acceleration, $\mathrm{m} / \mathrm{s}^{2}$

Gr Grashof number, $\mathrm{g} \beta \mathrm{qD}^{4} / \mathrm{k} v^{2}$

$h_{x} \quad$ Local convective heat transfer coefficient, $\mathrm{q} / \Delta \mathrm{T}_{\mathrm{s}}, \mathrm{W} / \mathrm{m}^{2} \mathrm{~K}$

$h_{m}$ Average convective heat transfer coefficient, , W $/ \mathrm{m}^{2} \mathrm{~K}$

$k$ Thermal conductivity, $\mathrm{W} / \mathrm{m} \mathrm{K}$

$L \quad$ Triangular channel length, $\mathrm{m}$

$N u_{x}$ Local Nusselt number, $\mathrm{h}_{\mathrm{x}} \mathrm{D} / \mathrm{k}$

$N u_{m}$ Average Nusselt number, $\mathrm{h}_{\mathrm{m}} \mathrm{D} / \mathrm{k}$

$\operatorname{Pr}$ Prandtl number, $\mathrm{c}_{\mathrm{p}} \mu / \mathrm{k}$

$Q \quad$ Electric power of main heater, $\mathrm{W}$

$q$ Heat flux, Q/A, $\mathrm{W} / \mathrm{m}^{2}$

$\mathrm{Ra}$ Rayleigh number, $\mathrm{Gr} \mathrm{Pr}$

$r_{a} \quad$ Average roughness, $\mathrm{mm}$

$T_{\infty} \quad$ Bulk air temperature, $\mathrm{K}$

$T_{s} \quad$ Inside surface temperature of triangular channel, $\mathrm{K}$

$T_{m s}$ Average inside surface temperature of triangular channel, $\mathrm{K}$

$T_{m f} \quad$ Mean film temperature, $\mathrm{K}$

$X \quad$ Axial distance measured from triangular channel entrance, $\mathrm{m}$

$\Delta T_{s}$ Temperature difference, $\left(T_{s}-T_{\infty}\right), \mathrm{C}$

Journal of Engineering Sciences, Assiut University, Faculty of Engineering, Vol. 41, No. 6, November, 2013, E-mail address: jes@aun.edu.eg 
Mohamed F. Abdeen et al., Natural convection heat transfer inside vertical and inclined open ended equilateral triangular channels, pp. 2160 - 2174

\section{Greek Letters}

$\beta \quad$ Volumetric coefficient of thermal expansion, $\mathrm{K}^{-1}$

$\mu \quad$ Dynamic viscosity of air, $\mathrm{kg} / \mathrm{m} \mathrm{s}$

$v$ Kinematic viscosity of air, $(\mu / \rho), \mathrm{m}^{2} / \mathrm{s}$

$\rho \quad$ Density of air, $\mathrm{kg} / \mathrm{m}^{3}$

$\theta$ inclination angle, degree

\section{References}

[1] Abdul-Aziz M. "Heat transfer by natural convection from the inside surface of a uniformly heated tube at different angles of inclination", M.S. Thesis, Mech. Eng. Dept., Al-Azhar University, Cairo, Egypt; (1991).

[2] Hussein A. and Yasin K. "Heat transfer by natural convection from a uniformly heated vertical circular pipe with different entry restriction configurations", Energy Conversion \& Management, 48 (2007) 2244-2253.

[3] Sarhan A., Kamis M. and Moawed M. "Heat transfer by natural convection in vertical and horizontal annuli", Al-Azhar Univ Eng. J. Vol. 4, No. 4, Cairo, Egypt; (2001).

[4] Hosseini R., Heyrani-Nobari M.,and Hatam M. "An experimental study of heat transfer in an open-ended vertical eccentric annulus with insulated and constant heat flux boundaries", Applied Thermal Engineering 25 (2005) 1247-1257.

[5] Omara M., Elshazly K., Moawed M. and Ibrahim E. "Heat transfer by free convection from the inside surface of the vertical and inclined elliptic tube", Energy Conversion \& Management, 46 (2005) 1443-1463.

[6] Moawed M. and Ibrahim E. "Free convection heat transfer inside vertical and inclined elliptic tubes with different axis ratio and different inclination and orientation angles", Energy Conversion \& Management, 49 (2008) 587-595.

[7] Amr O., Emad Z. and Sayed A. "Free convection from a constant heat flux elliptic tube" Energy Conversion and Management, 44 (2003) 2445-2453.

[8] Nada S.A. "Natural convection heat transfer in horizontal and vertical closed narrow enclosures with heated rectangular finned base plate", Int. J. of Heat and Mass Transfer, 50 (2007) 667-679.

[9] Varol Y., Koca A. and Hakan F., "Natural convection in a triangle enclosure with flush mounted heater on the wall", Int. Commun. in Heat and Mass Transfer, 33 (2006) 951-958.

[10] Seleem K. and Kamel A. "Experimental study of inclination angle and surface area effects for longitudinally finned cylinder on free convection heat transfer in an open enclosure" Journal of Engineering and Technology, Baghdad, Iraq Vol. 27, No. 5 (2009) 171-179.

[11] Abdlmonem B. and Michel A. "The effect of surface roughness on the average heat transfer of an impinging air jet", Int Commun in Heat and Mass Transfer, 27 (2000) 1-12

[12] Majid B., Michael M. and Richard J. "Role of random roughness on thermal performance of microfins", Journal of Thermophysics and Heat Transfer, Vol. 21, No. 1 (2007)153-157.

[13] Hany A., Omara M., Mahmoud S. and Mohamed F. "Experimental study of natural convection heat transfer through horizontal open ended equilateral triangular channels", Journal of Engineering Sciences, University of Assiut, Egypt. Vol. 40, No. 4 (2012) 10911103.

Journal of Engineering Sciences, Assiut University, Faculty of Engineering, Vol. 41, No. 6, November, 2013, E-mail address: jes@aun.edu.eg 
Mohamed F. Abdeen et al., Natural convection heat transfer inside vertical and inclined open ended equilateral triangular channels, pp. 2160 - 2174

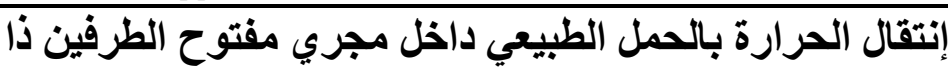

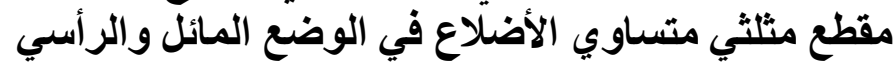

\section{الملخص العربى}

يقدم هذا البحث در اسة معملية لإنتقال الحرارة بالحمل الطبيعي داخل مجري مفتوح الطرفين ذا مقطع مثلتي

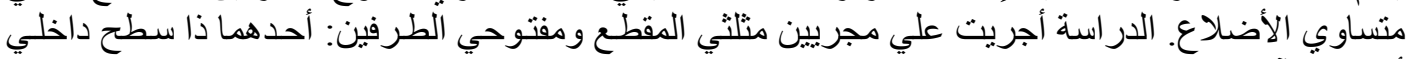
أملس والآخر ذا سطح داخلي خشن بدرجة خشونة متوسطة تساوي

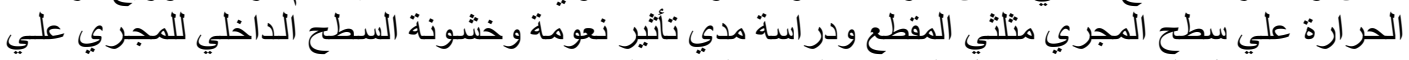

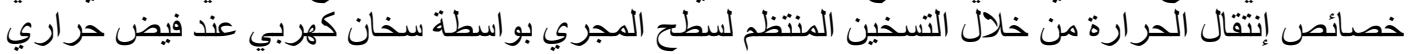

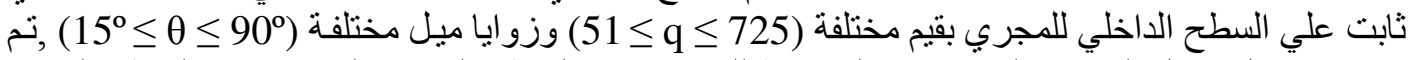

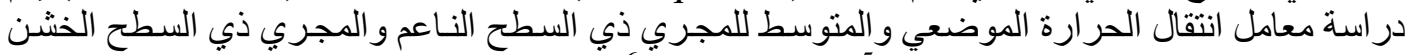

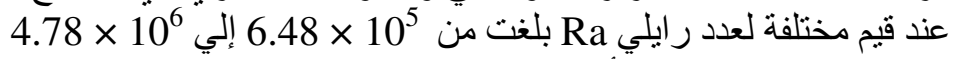

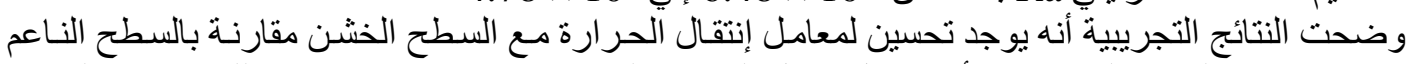

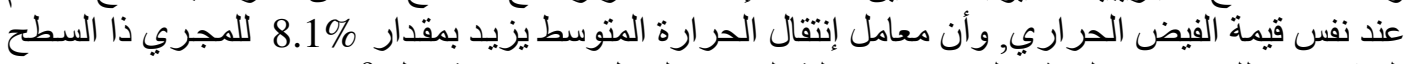

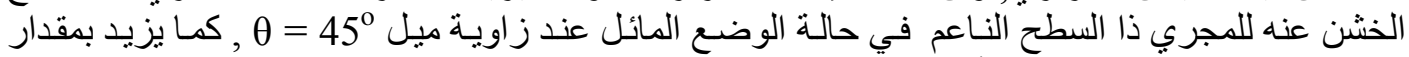

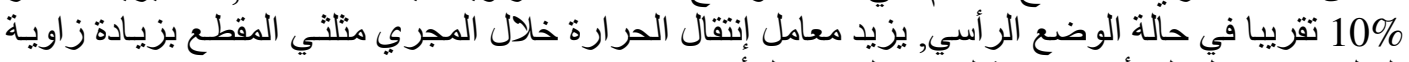

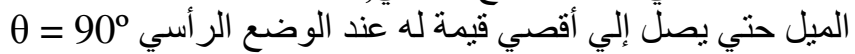
و قد تم الحصول علي معادلات تجريبية تربط العو امل الَّختلفة لإنتقال الحر ارة بالحمل الطبيعي خلال الأسطح

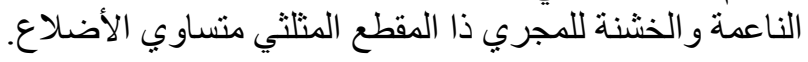

